\title{
Measurement of methane pressure by gas-pressure-measurement-tube sets in underground coalbeds
}

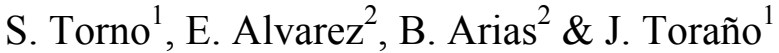

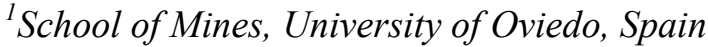 \\ ${ }^{2}$ Hullera Vasco Leonesa S.A. Santa Lucia, Leon, Spain
}

\begin{abstract}
Sudden methane outbursts which often cause serious accidents with numerous fatalities can be produced in underground coalbed roadways and when driving tunnels for highways or railways passing through carboniferous materials.

Most of the factors which take part in the generation of sudden outbursts are related to methane conditions into the coalbed and specifically to gas pressure and coal permeability.

When excavating roadways or tunnels crossing coalbeds, it is convenient to have easy to use equipment which allows us to know at any moment the measured pressure and its variation in factors such as roadway and tunnel driving velocity, geological faults which lead to fractured formations and natural or induced overstresses.

The designed gas-pressure-measurement-tube set goes into an $8 \mathrm{~m}$ deep and $45 \mathrm{~mm}$ in diameter borehole drilled in front of the working face. The gaspressure-measurement-tube set is connected to a flexible rod with a manometer at the end of it.

The obtained measurements are used both in the empirical formulae and in Computational Fluid Mechanics; this allows us to predict the probability of the occurrence of sudden outbursts.
\end{abstract}

Keywords: gas pressure, methane, outburst, gas-pressure-measurement tube, underground mine. 


\section{Introduction}

Outbursts in the underground coal mines have been and will be a highly topical question as a consequence of the repercussion which they have on miner safety.

The statistics of fatal accidents are unfortunately widespread and extensive in mines worldwide [1-3].

Alterations which are originated by mining works generate a reorder of tensional state of coalbed till it achieves a new equilibrium, being able to make different phenomena evident during these processes. This affects the stability of coal mine created and consequently the safety of the workers.

Under the denomination of dynamic phenomena, a set of manifestations, in a sudden way, due to existing energetic conditions emitted, are included. As a consequence, a process of projection of coal and rock which can be accompanied by the gas content in the coal is produced. These energetic conditions are generated by the interactions of the following three factors: tensional state of coalbed, presence of gas in the coal and in some cases gravity.

In figure 1, the triangular graphic which related the three factors giving way to the different types of gas emission phenomena is shown. Moreover, it can clearly be seen which properties are more influenced in these factors.

\section{Gas pressure}

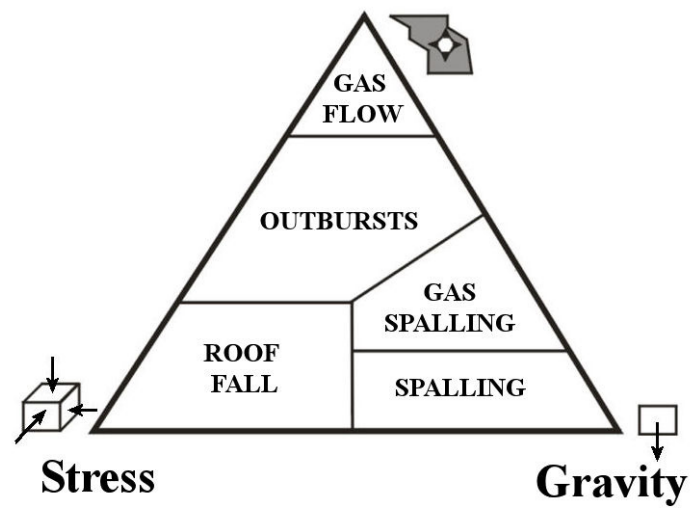

Figure 1: $\quad$ Triangular graphic of gas dynamic phenomena.

The outburst of coal and methane consists of sudden and violent interruption of coal methane in the vacuum created by an explosion $[4,5]$. This phenomenon correspond to a modification of the most favorable conditions for the disintegration of the coal close to the face and favours the intense and sudden desorption of methane ([6] and Coal Group of Energy Division of United Nations Economic Commission for Europe (UNECE) [7]).

In the Complementary Technical Instruction developed by the Principado de Asturias (legislation applicable to the location of the mine, S.A. Hullera Vasco Leonesa, and where the experimental measurements are carried out) outbursts of 
coal and gas are defined as 'one of the most complex gas dynamic phenomena' with the following characteristics:

-The sudden destruction of face with a common cavity in the coalbed.

-The pneumatic transport of broken coal.

-A higher gas outburst to the normal content of the coal, which is progressively reduced.

In underground coal mine of S.A. Hullera Vasco Leonesa, the outbursts could be classified as a medium type, since from $50-400 \mathrm{t}$ of coal are affected. In this study, $300 \mathrm{t}$ of coal were ejected and about $1000 \mathrm{~m}^{3}$ of gas have been emitted. This classification orders the outbursts in five groups from $0.5-10 \mathrm{t}$ to $>1000 \mathrm{t}$. Most of the factors which take part in the generation of sudden outbursts are related to methane conditions in the coalbed, especially to gas pressure and coal permeability.

In this paper, the necessity to make use of simple equipment which allows us to know at any moment the measured pressure and its variation in factors such as roadway and tunnel driving velocity, geological faults which lead to fractured formations and natural or induced overstresses is manifested.

For experimental measurements a gas-pressure-measurement tube set which goes into an $8 \mathrm{~m}$ deep and $45 \mathrm{~mm}$ in diameter borehole drilled in front of the working face is designed. This gas-pressure-measurement tube set is connected to a flexible rod with a manometer at the end of it.

A continuous record of the gas pressure measurements in the coalbed allows us to take preventive measures against the outbursts. This avoids the presence of outbursts and reduces the risk of serious accidents for the miners.

\section{Risk indexes}

There are numerous indexes which quantify the different factors that determine the presence of outburst, some of them are the following: methane concentration in coalbed [8], desorption velocity of methane [9], methane concentration in ventilation, V30 and the German Regulation [10], drill cuttings - Jahns test [11], measurements of gas pressure in the roadway and coalbed [2], the Polish ST index [12], the Russian Ps index, from WostNII Institute in Kuznetsk, the Psi index from the Karaganda coalfield in Kazakhstan and the $\mathrm{k}$ and D indexes from China [13].

The nature of these indexes are variable, from normal ones (some of them are applied in other disciplines) to those which are both consider mining experiences and useful.

In both simple indexes and combined indexes, the gas pressure is of greater importance; therefore, it is the most important factor studied in this research.

There are two types of gas pressure measurements in coalbed: measurements in the coalbed and measurements in the heading face. The first measurements which correspond to the phase of coalbed research have been carried out by means of boreholes of greater length where a gas-pressure-measurement tube set which registers the evolution of the gas pressure in long periods of time has been placed. 
The pressure changes according to the depth where the results are expressed by means of quotient between the gas pressure and lithostatic pressure. Measurements and control of gas pressure at a few meters.

These techniques associated with exploitation works have been carried out in a mine in Czech Republic, and consist of a daily systematic measurement of the gas pressure in boreholes of $3 \mathrm{~m}$ in depth and $42 \mathrm{~mm}$ in diameter.

This measurement instrument consists of a tube equipped with a sealing system connected to a manometer or monitoring system.

The measurements are stabilized every 3 minutes. The critical values of this index are specified in each coalbed and are stabilized by numerous sets of measurements. The most common gas pressure value findings are approximately $50 \mathrm{kPa}$.

In 166 analyzed outbursts, in various coalfields such as Jagorszynski, Kuznetsk, Donetsk or Karaganda, the following conclusions, related to the influence of the gas pressure, have been detected [13]:

-No outbursts have been recorded for gas pressure below $6 \mathrm{MPa}$.

-For pressure between 0.6 and $0.74 \mathrm{MPa}, 79$ outbursts were generated with a maximum intensity of 2977 and a medium of $54 \mathrm{t}$.

-For pressure above $0.74 \mathrm{MPa}, 87$ outbursts were generated with a maximum intensity of $1500 \mathrm{t}$ and a medium of $145 \mathrm{t}$.

\section{Gas-pressure-measurement tube set}

Hullera Vasco Leonesa S.A. Company located in the province of Leon in the North of Spain, is an underground coal mine with three shafts connected between them. The annual coal production is 2 million tons and the proved exploitable coal reserves at the end of 2009 are 45 million tons.

The average coal properties of the mined coalbed are $12.39 \%$ Ash, $0.75 \%$ Sulfur, $10.41 \%$ Volatiles, Calorific value of $7455 \mathrm{Kcal} / \mathrm{Kg}$ and Density 1.45 $\mathrm{kg} / \mathrm{m}^{3}$ Density.

Stratigraphically, the coal basin is divided into six well-defined formations. The whole group is about $1,500 \mathrm{~m}$ thick, formed about 300 million years ago. Pastora Formation shows the best economic prospects and it provides the totality of the present coal production. The Pastora coalbed varies in thickness from 20 to $25 \mathrm{~m}$, its dip is between $40^{\circ}$ and $70^{\circ}$ and the methane concentration varies between 7 and $10 \mathrm{~m}^{3} / \mathrm{t}$ of coal.

The exploitation of this coalbed where the outbursts were produced was exploited by two methods, sublevel caving and shortwall between two levels [14]. The mining method by shortwall and sublevel caving is performed with a particular system of shield supports. The panel width varies according to the thickness of the coalbed. The large coalbed thickness contributes the generation of outbursts [13].

The Mining Company S.A. Hullera Vasco Leonesa has designed a tool in order to measure the gas pressure. Firstly, the tool or gas-pressure-measurement tube was created piece by piece in the SolidWorks software as shown in figure 2, where ' 1 ' is the length in meters and ' $\mathrm{d}$ ' is the diameter also in meters. 


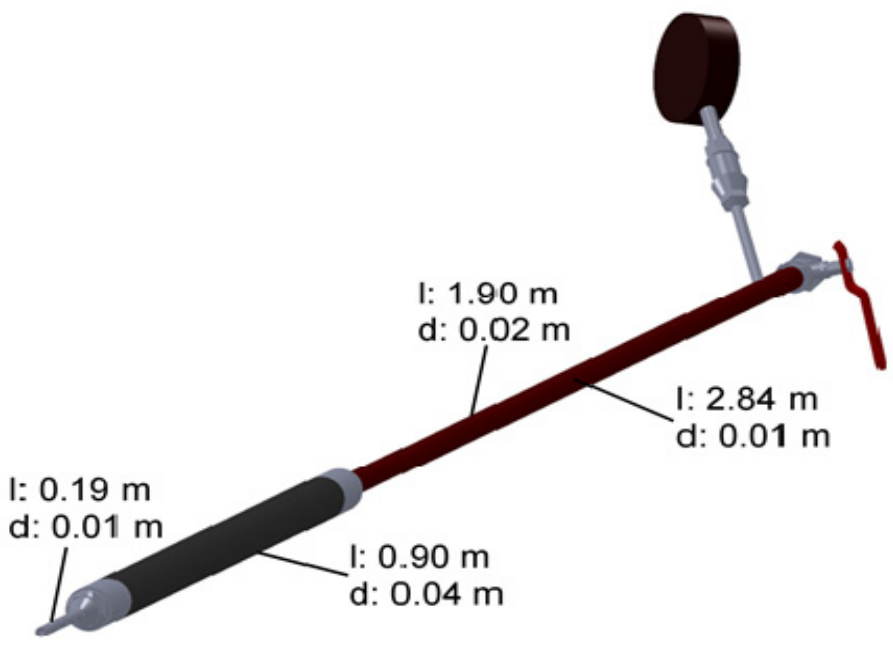

Figure 2: Diagram of gas-pressure-measurement tube designed by SolidWorks.

Secondly, the gas-pressure-measurement tube was manufactured by S.A. Hullera Vasco Leonesa, as it is illustrated in figure 3.

In figure 3 the gas-pressure-measurement tube is illustrated with its final configuration, demonstrating the following parts:

-Measurement tube (1).

-Sealing system (2).

-Borehole rod (3).

-Manometer or monitoring system (4).

-Borehole rod (5) to inject water at a pressure of 1.96 MPa used for the sealing system.

When it is necessary to introduce this tube into deeper boreholes it is lengthened by means of an extensible flexible tube.

The boreholes used for inserting the gas-pressure-measurement tube sets were carried out at the crown of the heading face. They were $8 \mathrm{~m}$ in length, $45 \mathrm{~mm}$ in diameter and $10^{\circ}$ angles in upward direction.

The gas-pressure-measurement tubes were put into operation at night, on Friday nights, in order to take gas pressure evolution measurement at heading face until seven o'clock on Monday morning.

When the gas pressure measurements were performed, the heading face was degassed with 6 boreholes at the crown of $3.2 \mathrm{~m}$ in length and $65 \mathrm{~mm}$ in diameter, and in the middle with 3 boreholes of $5.6 \mathrm{~m}$ in length and $105 \mathrm{~mm}$ in diameter. 

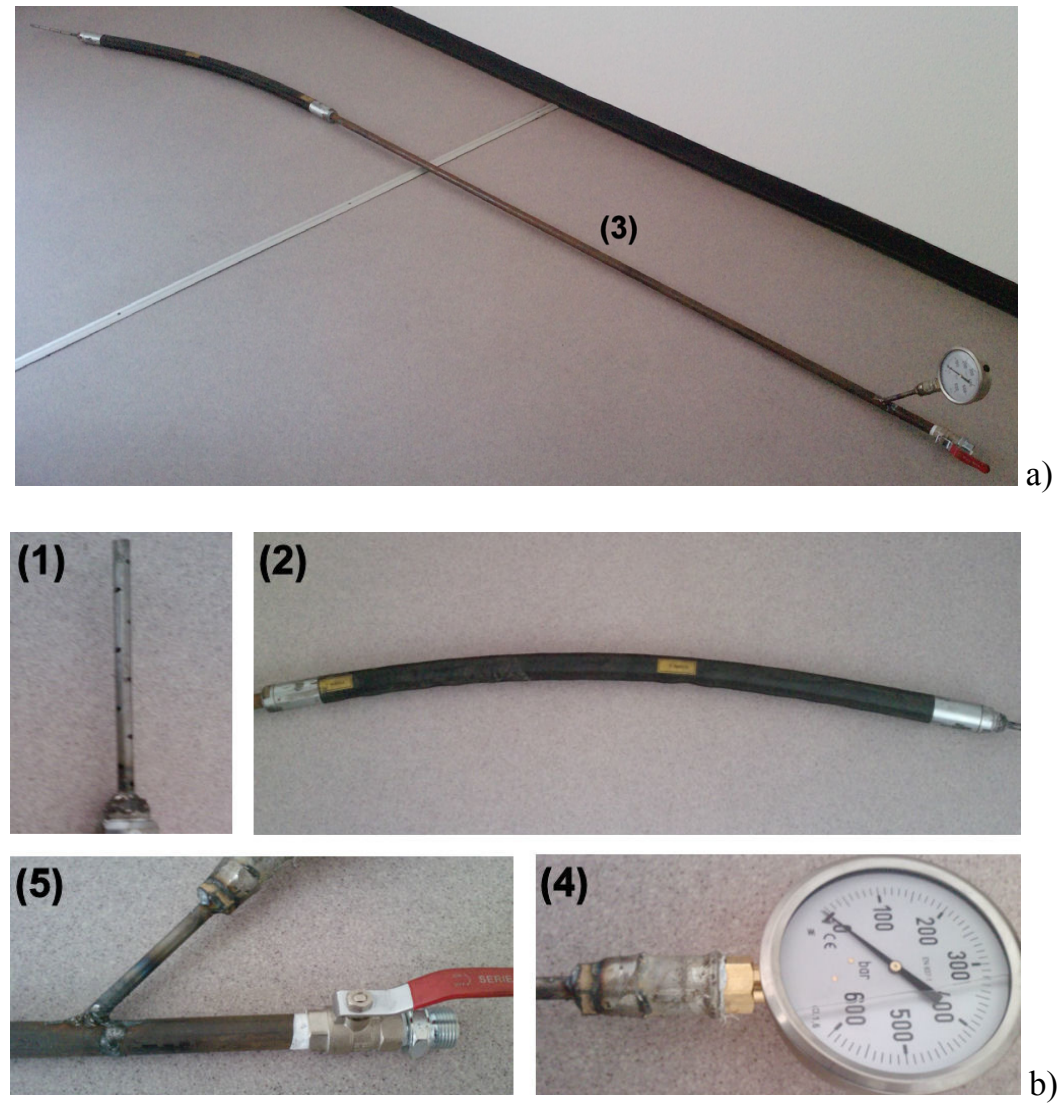

Figure 3: Gas-pressure-measurement tube prior to being introduced into the boreholes.

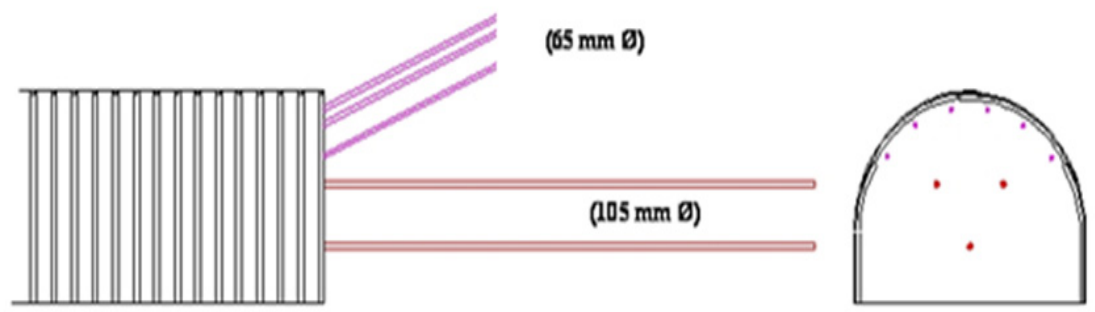

Figure 4: Description of boreholes where the gas-pressure-measurement tube is inserted in order to carry out the measurements. 
The horizontal distance that separates the face of heading and face of shortwall-sublevel caving is denominated ' $\mathrm{D}$ '. This distance changes as the mine is being exploited and can be divided into 3 groups:

-D is positive when the two faces become closer.

-D is 0 when the two faces coincide.

$-\mathrm{D}$ is negative when the faces overlap.

Figure 5 illustrates the results of the evolution over time of gas pressure $(\mathrm{kPa})$ in 3 boreholes in the roof for five distances $\mathrm{D}=33,23,2,-11.5$ and $-40 \mathrm{~m}$.

It can be seen how, for four hours after inserting the measurement tube $(\mathrm{D}=30 \mathrm{~m})$, there is an increase in the gas pressure reaching maximum values of $900 \mathrm{kPa}$.

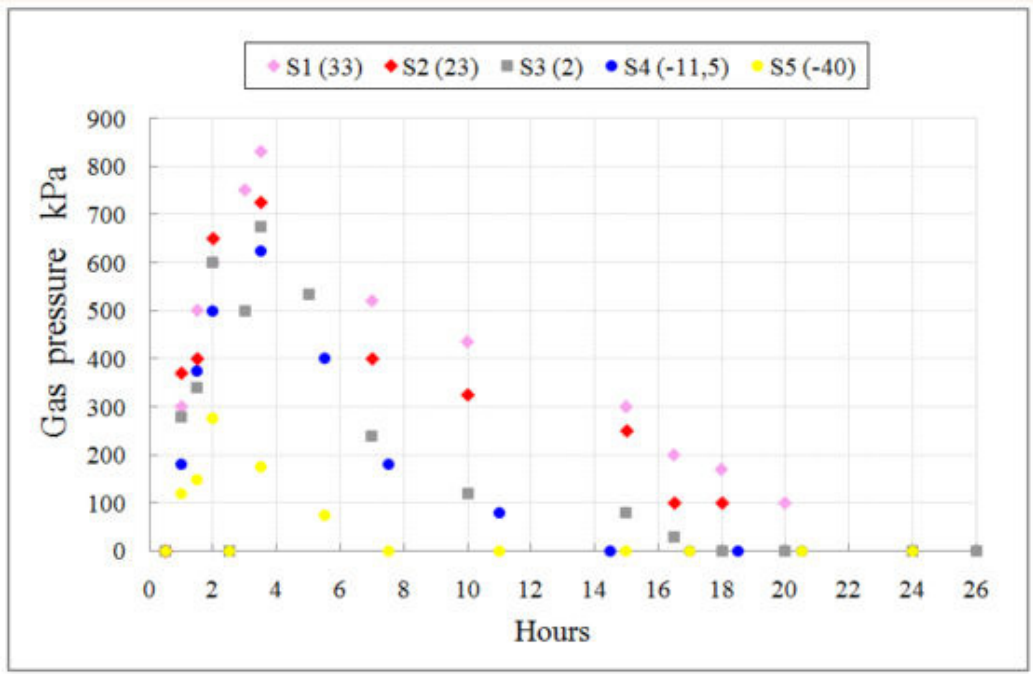

Figure 5: Evolution of the gas pressure in the coalbed in function on distance $\mathrm{D}$ and time.

When $\mathrm{D}$ decreases, the maximum gas pressure also decreases, reaching values below $700 \mathrm{kPa}$. Later a faster decrease in this pressure occurs over time until becoming 0 .

When the distance $\mathrm{D}$ is negative, the maximum values of gas pressure are lower than $500 \mathrm{kPa}$ and when the absolute value of $\mathrm{D}$ is higher, the maximum pressure is $300 \mathrm{kPa}$.

The evolution of the gas pressure shows that there is an outburst-prone zone as a consequence of a gas pressure increase for the distance D (between 25 and $50 \mathrm{~m})$.

For lower values of $\mathrm{D}$, as a result of the decrease in the Protodiakonov index of the heading face (average values of 1.31, maximum values of 2.13 and 
minimum values of 0.51 ), the danger of the occurrence of an outburst diminishes, and the problems related to methane blows increase [13].

\section{Conclusions}

The measurements and evolution of gas pressure by boreholes in the heading face allow us to predict by means of simple and operative tools, the trend of the generation of outbursts in the coalbed.

It is convenient for the gas-pressure-measurement tube to be motorized in order to have a remote and continuous register of the gas pressure.

When higher elevations of gas pressure, indicated by the gas-pressuremeasurement tube are generated, the coalbed should be degassed by means of boreholes in the heading face with an injection of pressure water.

If the pressure increase is excessive, penalization of the works could be necessary.

\section{References}

[1] Belin, J. \& Vandeloise, R., Résultats des recherches efectúes en Belgique et en France sur les dégagements instantanés dans les mines de charbon. Annales des Mines de Belgique. No 2 Février, 1969.

[2] Lama, R.D. \& Bodziony, J., Management of outburst in underground coal mines International Journal of Coal Geology, 35, pp. 83-115, 1998.

[3] Basil Beamish, B.B. \& Crosdale, P.J., Instantaneous outbursts in underground coal mines: An overview and association with coal type International. Journal of Coal Geology, 35, pp. 27-55, 1998.

[4] Peng, S.S, Coal mine ground control. John Wiley \& Sons. New York 1986.

[5] Hargraves, A.J., Update on instantaneous outbursts of coal and gas. Proceeding of Australian Institute of Mining and. Metallurgy, 298, pp. 317, 1993.

[6] Belin, J., Mesures de prevention des degagement instantanés de methane et de charbon ou de roches. Organe permanente pour la securité et la salubrité dans les mines de houlle. $\mathrm{N}^{\circ}$ 6039/81. Luxembourg, 1983.

[7] ECE, Coal Group of Energy Division of United Nations Economic Commission for Europe. Luxembourg, 1995.

[8] ET0307-2-92. Especificación técnica: Método para determinar la concentración de gas en la capa. Ministerio de Industria del Estado Español.

[9] ET0307-2-92. Especificación técnica: Método para determinar la velocidad de desorción del grisú. Ministerio de Industria del Estado Español.

[10] Renania, Circulares 23.10.87, 6.7.82 y 13.8.81 de la Dirección Superior de Minas del Estado de Renania sobre DI. Dormund. Verlag. H. Bellmann, 1987.

[11] Bräuner, G., Rockburst in coal mines and their prevention. Ed. Balkema. Rotterdam, 1994. 
[12] Tarnowski, J., Calculations concerning coal and gas outburst. International Symposium of Workshop on Management, Control of High Gas Emission and Outburst. Ed. Lama. Wollongong, pp. 49-61, 1995.

[13] Lama, R.D., Bodziony, J., Sudden outburst of gas and coal in underground coal mines. Final Report. Project No. C 3034. Australian Coal Association Research Program, 1996.

[14] Toraño, J., Torno, S., Menéndez, M., Gent, M.R., Velasco, J., Models of methane behaviour in auxiliary ventilation of underground coal mining. International Journal of Coal Geology, 79, pp. 157-166, 2009. 